\title{
Constructing preferences in the physical world: a distributed- cognition perspective on preferences and risky choices
}

\section{Gaëlle Villejoubert* and Frédéric Vallée-Tourangeau}

Department of Psychology, Kingston University London, Kingston Upon Thames, UK

*Correspondence: g.villejoubert@kingston.ac.uk

Psychological research has firmly established that risk preferences are transient states shaped by past experiences, current knowledge, and feelings as well as the characteristics of the decision environment. We begin this article with a brief review of evidence supporting this conception as well as different psychological theories explaining how preferences are constructed. Next, we introduce the distributed perspective on human cognition and show how it may offer a promising framework for unifying seemingly incompatible accounts. We conclude by suggesting new directions for better capturing the essence of preference construction in laboratory research.

\section{ON THE PSYCHOLOGY OF HUMAN PREFERENCES AND RISKY CHOICES}

Psychologists have long assumed that core cognitive processes such as memory, perception, and attention are inherently constructive - they are the product of the content of thoughts and the situation within which people are embedded when they think (Bartlett, 1932; Neisser, 1967). Risk preferences are no exception. As Lichtenstein and Slovic (2006,p. 1) put it: "in many situations we do not really know what we prefer; we must construct our preferences as the situation arises." Scholars often situate the origins of the concept of preference construction in Simon's $(1956,1990)$ focus on the bounded capacities of the human information-processing system on the one hand, and the shaping properties of the environment within which decisions are made, on the other. In Simon's words "Human rational behavior ... is shaped by a scissors whose two blades are the structure of task environments and the computational capabilities of the actor" (Simon, 1990, p. 7).

The notion that preferences are constructed is supported by a body of evidence that is both vast and varied. Lichtenstein and Slovic's (1971) work on preference reversals demonstrated the key role of response mode - bidding for a bet vs. choosing a bet - in shaping preferences for risky gambles. The work of Tversky and Kahneman's (1981) on choice framing illustrated how the superficial framing of the description of options can cause a reversal in risk preferences - from risk-seeking preferences in a choice between options framed with losses to risk-averse preferences when the same choice is framed with gains. More recently research has shown that preferences may also depend on how outcomes are experienced - either as a descriptive summary, or through actual sampling (Hertwig et al., 2004). Meanwhile, the impact of transient states such as affect and feelings on risk judgments (Slovic et al., 2002) further corroborates the conception of preferences as situated in time and space.

Several theories have been proposed to explain how preferences and associated decisions may be constructed. Some conceive preference construction as resulting from the impact of the environment on individuals' strategy choice or representations. The ecological approach (e.g., Brighton and Todd, 2009) proposes that the mind is endowed with an "adaptive toolbox" containing purpose-built simple decision heuristics that exploit the structure of the information in the immediate environment. The choice goals framework (Bettman et al., 1998) also assumes that individuals possess a repertoire of choice heuristics, acquired through experience or training. From these perspectives, an environment with a particular information structure will shape cognition by inviting the application of the decision heuristic that is most adapted to this structure. Similarly, accounting for risky choice framing, prospect theory (Kahneman and Tversky, 1979) suggests that the environment affects risk preferences and decisions through its impact on individuals' representations - as opposed to its impact on strategy selection - as decisions outcomes may be represented as gains or losses, depending on the reference point made salient in the task environment. Meanwhile, other theories characterized preference construction as an internal process where the role of the individual's immediate environment is less prominent. Svenson's (1996) differentiation and consolidation (DiffCon) theory posits that construction occurs through cycles of alterations of the decision task's mental representation in order to single out the alternative of choice. Search for dominance structure (SDS) theory (Montgomery, 1998) offers a similar conception where preferences are assumed to arise from the restructuring of the mental representation of attribute information to identify the dominant alternative. Svenson (1996) does note that context and decision structure may influence the decision rules that are elicited. Montgomery (1998) adds that "individual may also intervene in the external world to increase the support for the to-be-chosen alternative" (p. 287, emphasis added) but he does not specify what those interventions may be, what might be intervened upon, or by which mechanisms such interventions may result in increased support.

While these theories stress important features of the constructive process of preferences, we also believe that they offer an incomplete view of this process because they omit an essential aspect of how people may naturally construct their preferences: through their actions on their immediate environment. In the next section of this article, we present a theoretical framework that places interactivity at the forefront of efforts to understand choice preferences.

\section{BEYOND SITUATED COGNITION: COGNITION DISTRIBUTED}

A group of cognitive scientists, initially drawn from cognitive ergonomics and anthropology, have lobbied for a shift in the main unit of analysis to understand thinking (e.g., Hollan et al., 2000). They reject a traditional model of the mind where cognition is sandwiched between perceptual inputs and behavioral outputs 
(to adapt Hurley, 2001). Instead they argue that cognition is the product of a distributed system that reflects the dynamic meshwork of resources internal to the reasoner (such as cognitive capacities, acquired knowledge) as well as resources external to the reasoner (such as artifacts, people, cultural beliefs; Kirsh, 2009, 2010; Hutchins, 2010). A key notion in the systemic perspective is that people interact with external resources to augment and facilitate thinking. From a distributed-cognition perspective, thinking is the product of embodied and embedded mental and physical activities. In other words, people do not just "think with their heads," they also "think with their eyes and hands" in an environment that affords interaction. This results in an extended cognitive system (Wilson and Clark, 2009), akin to an ecological niche (cf. Laland et al., 2000) enabling people to exceed the capacities of their unaided, non-extended mind.

People act upon their environment when they think, and more specifically when they evince a preference, in a rich and varied manner; yet this activity is rarely the focus of research. People, generally, do not choose their homes or their cars from written descriptions. Rather, they walk in potential flats, project and sketch furniture placement, open and close wardrobes, sit on the terrace to help simulate what it would be like to live in the place. In other words, they do not only adapt to their environment, they actively shape, manipulate, and interact with it to support their decision-making.

The distributed perspective has been the subject of ethnographic analysis "in the wild" (Hutchins, 1995), but it can also guide more controlled experimental work (Fioratou and Cowley, 2009; Weller et al., in press). For example, we recently examined performance on matchstick algebra problems which present participants with a false algebraic equation made of matchsticks and require them to move one matchstick to form a true equation (Knoblich et al., 1999). Adopting a distributed-cognition perspective, we compared performance on the traditional paper-and-pencil version of the task with performance in an interactive version where participants could physically manipulate the matchsticks, using a modifiable, three-dimensional, physical presentation of the equation. Participants in the interactive group were significantly more likely to achieve insight to transform these expressions into true equations. Moreover, whereas numeracy predicted performance in the paper-and-pencil group, performance was best predicted by visuo-spatial reasoning skills in the interactive group. These results suggest that different types of resources and skills were recruited in the interactive and non-interactive versions of the task, respectively.

The distributed-cognition perspective may also offer a novel way to conceive the role of the environment in the construction of preferences. The theoretical frameworks reviewed earlier assume that the environment shapes cognitive activity. In experiments used to test these approaches, however, the environment is often presented in a two-dimensional, fixed presentation akin to the non-interactive version of the matchstick algebra task, offering linguistic or numerical information that is presented in essentially inflexible and intangible formats. These environments severely limit individuals' natural tendency to think with their eyes and hands. The distributed-cognition perspective could offer a new window onto the process of preference construction, focusing on the coupling between people's cognition and the strategic and opportunistic manipulation of the information populating their immediate physical space. As Weller et al.'s (in press) study illustrates, adopting a distributed perspective on cognition does not necessitate studying cognitive activities in naturalistic settings. In fact, we believe that the potential of this approach resides in its promise to better capture the essence of cognitive processes in general, and preference construction in particular, within laboratory settings.

Adopting a distributed-cognition perspective also highlights a potentially invalid assumption underpinning alternative accounts of preference construction, such as SDS theory (Montgomery, 1998) and the DiffCon theory (Svenson, 1996) reviewed above - and more generally, numerous theories accounting for higher level cognitive processes - namely, the assumption that the mental restructuring of a rigid presentation of the informational landscape is equivalent to the physical restructuring of this landscape, in the individual's immediate environment. It is not: an inflexible physical problem presentation exerts gravity on people's effort to depart from and transform their representation of the information; whereas a dynamic one may better support the development of a productive representation of the problem information.

Concretely, better understanding how preferences may be constructed in the physical world will involve designing experimental settings where participants are no longer limited to alter the information presented to them mentally. This, we surmise, will lead to a revision of the amount of information that people are actually capable of computing when constructing preferences. For example, a canonical representation of the information in choice framing tasks such as the Asian Disease problem (Tversky and Kahneman, 1981) requires taking into account all outcomes of concurrent decisions. Such a bias-free representation has been previously ruled out as psychologically implausible, assuming that it would exceed human computational capabilities (Kahneman and Tversky, 1984). Maule and Villejoubert (2007) surmised that participants might instead mentally switch between a gain-framed representation and a loss-framed representation, in a similar manner to the perspective-switching occurring when people are presented with ambiguous figures such as the Necker cube. Choice behavior would then be determined by the dominant representation at the moment of choice. Taking a distributed-cognition approach to study choice framing, one could use playing cards presenting a positive or negative outcome associated with each of two alternatives. Probabilities of outcomes would be presented as the relative proportion of positive and negative outcomes. This would enable participants to manipulate, spread, arrange and rearrange the cards, and perhaps contrast losses and gains while constructing their preference. Importantly, rather than constrain thinking, the manipulability afforded by the material presentation of the information would instead support if not augment - people's computational abilities. In such a situation, the mental switch of focus between a gain-framed and a loss-framed representation (Maule and Villejoubert, 2007) could then be supported by the physical presentation of the information and thus, considerably reducing the mental efforts required for switching focus. Moreover, this would make the 
process of restructuring directly accessible to the researcher, through the observation and coding of the actions and eye-gazes executed by the decision-makers.

To conclude, Simon's (1956, 1990) emphasis on the major shaping role played by the environment within which decisions are made has often been used to explain how preferences are constructed. Simon's argument has often been summarized as focusing on the "interaction" between individuals' mental activities and their immediate environment (e.g., Brighton and Todd, 2009, p. 339; Lichtenstein and Slovic, 2006, p. 23; Bettman et al., 1998, p. 187). However, interactivity as such never figures in either Simon's (1956, 1990) account or in subsequent theoretical efforts. Some have developed theories explaining how decision-makers may select choice heuristics that are fitted to the structure of the environment. Others have stressed the importance of the mental restructuring of the information in preference construction. In this article we sought to illustrate how neither approaches can fully account for the essence of preference construction as it may occur in natural settings. We propose that this is because past research has neglected an important aspect of cognition - viz., how interactions with the world may influence and support mental processes. Whether, under what conditions, and by which processes, freeing up decision-makers' hands may indeed affect the way they construct their preferences, may thus prove to be an important new avenue for research.

\section{REFERENCES}

Bartlett, F. C. (1932). Remembering. Cambridge: Cambridge University Press.
Bettman, J. R., Luce, M. F., and Payne, J. W. (1998). Constructive consumer choice processes. J. Consum. Res. 25, 187-217.

Brighton, H., and Todd, P. M. (2009). "Situating rationality: ecologically rational decision making with simple heuristics," in The Cambridge Handbook of Situated Cognition, eds P. Robbins and M. Aydede (New York, NY: Cambridge University Press), 322-346.

Fioratou, E., and Cowley, S. (2009). Insightful thinking: cognitive dynamics and material artifacts. Pragmat. Cogn. 17, 549-572.

Hertwig, R., Barron, G., Weber, E. U., and Erev, I. (2004). Decisions from experience and the effect of rare events in risky choice. Psychol. Sci. 15, 534-539.

Hollan, J., Hutchins, E., and Kirsh, D. (2000). Distributed cognition: toward a new foundation for human-computer interaction research. ACM Trans. Comput. Hum. Interact. 7, 174-196.

Hurley, S. L. (2001). Perception and action: alternate views. Synthese 129, 3-40.

Hutchins, E. (1995). Cognition in the Wild. Cambridge, MA: MIT Press.

Hutchins, E. (2010). Cognitive ecology. Top. Cogn. Sci. 2, 705-715.

Kahneman, D., and Tversky, A. (1979). Prospect theory: an analysis of decision under risk. Econometrica 47, 263-291.

Kahneman, D., and Tversky, A. (1984). Choices, values, and frames. Am. Psychol. 39, 341-350.

Kirsh, D. (2009). "Interaction, external representation and sense making," in Proceedings of the Thirty First Annual Conference of the Cognitive Science Society, eds N. A. Taatgen and H. V. Rijn (Austin, TX: Cognitive Science Society), 1103-1108.

Kirsh, D. (2010). Thinking with external representations. AI Soc. 25, 441-454.

Knoblich, G., Ohlsson, S., Haider, H., and Rhenius, D. (1999). Constraint relaxation and chunk decomposition in insight problem solving. J. Exp. Psychol. Learn. Mem. Cogn. 25, 1534-1555.

Laland, K. N., Odling-Smee, J., and Feldman, M. W. (2000). Niche construction, biological evolution, and cultural change. Behav. Brain Sci. 23, 131-175.

Lichtenstein, S., and Slovic, P. (1971). Reversals of preference between bids and choices in gambling decisions. J. Exp. Psychol. 89, 46-55.

Lichtenstein, S., and Slovic, P. (2006). "The construction of preference: an overview," in The Construction of
Preference, eds S. Lichtenstein and P. Slovic (New York, NY: Cambridge University Press), 1-40.

Maule, J., and Villejoubert, G. (2007). What lies beneath: reframing framing effects. Thinking Reasoning 13, 25-44.

Montgomery, H. (1998). "Decision making and action: the search for a dominance structure," in eds Personal Control in Action, M. Kofta, G. Weary, and G. Sedek (New York, NY: Plenum Press), 279-298.

Neisser, U. (1967). Cognitive Psychology. New York, NY: Meredith.

Simon, H.A. (1956). Rational choice and the structure of the environment. Psychol. Rev. 63, 129-138.

Simon, H.A. (1990). Invariants of human behavior. Annu. Rev. Psychol. 41, 1-19.

Slovic, P., Finucane, M. L., Peters, E., and Macgregor, D. G. (2002). "The affect heuristic," in Heuristics and Biases: The Psychology of Intuitive Judgment, eds T. Gilovich, D. Griffin, and D. Kahneman (New York, NY: Cambridge University Press), 397-420.

Svenson, O. (1996). Decision making and the search for fundamental psychological regularities: what can be learned from a process perspective? Organ. Behav. Hum. Decis. Process. 65, 252-267.

Tversky, A., and Kahneman, D. (1981). The framing of decisions and the psychology of choice. Science 211, 453-458.

Weller, A., Villejoubert, G., and Vallée-Tourangeau, F. (in press). Interactive insight problem solving. Think. Reason.

Wilson, R.A., and Clark,A. (2009). "How to situate cognition: letting nature take its course," in The Cambridge Handbook of Situated Cognition, eds P. Robbins and M.Aydede (Cambridge: Cambridge University Press), 55-77.

Received:07 July 2011; accepted: 11 October 2011; published online: 15 November 2011.

Citation: Villejoubert $G$ and Vallée-Tourangeau $F$ (2011) Constructing preferences in the physical world: a distributed-cognition perspective on preferences and risky choices. Front. Psychology 2:302. doi: 10.3389/fpsyg.2011.00302 This article was submitted to Frontiers in Cognition, a specialty of Frontiers in Psychology.

Copyright (c) 2011 Villejoubert and Vallée-Tourangeau. This is an open-access article subject to a non-exclusive license between the authors and Frontiers Media SA, which permits use, distribution and reproduction in other forums, provided the original authors and source are credited and other Frontiers conditions are complied with. 